\title{
Bezmialem Vakıf Üniversitesi Tıp Fakültesi Araştırma Eğitiminde Uygulanan Bilimsellik Yatay Stajı ve Değerlendirme Sonuçları*
}

\section{Scholarly Concentration and Evaluation Results Applied in Research Education in Bezmialem Vakif University Faculty of Medicine}

\author{
Semra Özçelik (ORCID ID: https://orcid.org/0000-0001-9237-6723) \\ Dilek Sema Artcı (ORCID ID: https://orcid.org/0000-0003-2104-1349) \\ Meliha Meriç Koç (ORCID ID: https://orcid.org/0000-0002-0563-6900) \\ Rümeyza Kazancıoğlu (ORCID ID: https://orcid.org/0000-0003-1217-588X) \\ Bezmialem Vakıf Üniversitesi Tıp Fakültesi \\ *X. Ulusal Tıp Eğitimi Kongresi'nde poster olarak sunulmuştur, İzmir, 2018.
}

\begin{abstract}
ÖZET
Anahtar Sözcükler: Tıp Eğitimi, Araştırma Eğitimi, Bilimsellik

Keywords: Medical education, Research education, Scholarly

Gönderilme Tarihi

Submitted:18.02.2019

Kabul Tarihi

Accepted: 13.05.2019

Amaç: Her öğrencinin sorumluluğunu üstlenerek, bilimsel bir araştırma yapmasını sağlayacak "Araştırma Eğitimi Programı" fakültemizde klinik dönemde "Bilimsellik Stajı" adı verilen bir stajla gerçekleşmektedir. Bu çalışmanın amacı, uygulamanın nasıl yapıldığı ve değerlendirildiğini açıklamak ve edinilen deneyimleri paylaşmaktır.

Gereç ve Yöntem: Bu stajda, amacı ve içeriği belirlenmiş altı modülde, araştırma eğitimine yönelik konferanslar ve öğrencilerin danışmanları ile birlikte hazırlamış oldukları araştırmaların aşamaları yer almaktadır. Öğrenciler, kendilerine bir danışman öğretim üyesi seçmekte ve bu öğretim üyesiyle standart bir sözleşme imzalamaktadırlar. Bu programın planlanmas1, yürütülmesi ve kontrolünü yapan ve Bilimsellik Staj1 Komisyonu (BSK) adı verilen bir komisyon oluşturulmuştur. İlk modülden itibaren öğrencilerin danışmanları ile birlikte bir araştırma sorusu oluşturmaları, bilimsel literatür taramaları yapmaları, etik kurul onayı almaları ve gerektiğinde proje hazırlayarak Bilimsel Araştırma Projeleri Birimi'ne başvurmaları gerekmektedir. İstatistiksel destek alma, araştırmayı sürdürme ve bitirme sorumlulukları da bulunmaktadır.
\end{abstract}

Makale Künyesi: Bezmialem Vakıf Üniversitesi Tıp Fakültesi Araştırma Eğitiminde Uygulanan Bilimsellik Yatay Stajı ve Değerlendirme Sonuçları. Tıp Eğitimi Dünyası. 2019;18(55): 70-79 
Modüllerde öğretim üyeleri tarafından konferanslarverilmekteveküçük gruplaraayrılan öğrenciler, projelerinin aşamalarını komisyonda yer alan öğretim üyesi ve grup arkadaşlarına sunmaktadır. Her modülün gerektirdiği aşamalar belirlenmiş ve bir kılavuzda yayınlanmıştır. Öğrenciler, üç yarıyıl süren stajın sonunda Tıp Bayramı'nda düzenlenen "Araştırma Günü” etkinliklerinde sözlü veya poster bildirileri şeklinde araştırmalarını sunmaktadırlar. BSK uygulamayı düzenlemekte, modüllerde görev almakta ve tüm taraflardan alınan geribildirimleri değerlendirerek üst birimlere rapor etmektedir. Uygulamayı eşgüdümlü olarak yürüttüğümüz Johns Hopkins Üniversitesi öğretim üyeleri de her modüle katkı sunmaktadır. Ölçme ve değerlendirme, modüllerde gösterdikleri ilerlemelere göre, yapılandırılmış bir puanlama sistemiyle gerçekleştirilmektedir.

Bulgular: Bilimsellik staj1 2015-2016 Eğitim - Öğretim yılında Dönem IV le başlamış ve 14 Mart 2017 tarihinde toplam 93 araştırma tamamlanarak sözlü bildiri ya da poster olarak, bir sonraki dönem devam eden 100 öğrenci de 14 Mart 2018 tarihinde aynı şekilde araştırmalarını başarıyla tamamlayarak sunmuştur. Halen Dönem IV de 130, Dönem V'de 126 öğrenci araştırma projelerini gerçekleştirmek üzere çalışmalarına devam etmektedir. 193 öğrencinin araştırma özetleri, Bezmialem Science dergisinin ek sayısında yayınlanmış olup, her yıl tamamlanan projelerin bu şekilde yayınlanması planlanmıştır.

Sonuç: Bilimsellik Stajı, BVÜ Tıp Fakültesi program çıktılarında da yer alan «Bilimsellik» maddesi kapsamında, öğrencilerimize bilimsel okur-yazarlığı öğretmek amaçlı oluşturulmuştur. BVÜ öğrencilerinin bu aşamaları birebir yaşayarak ve yaparak öğrenmelerinin eğitimlerine önemli katkısının olacağını düşünmekteyiz. Benzer uygulamaların yaygınlaşmasının ülkemizde araştırmacı-hekim sayısında artış sağlayacağı kanısındayız.

\section{SUMMARY}

Aim: Research Training Program, which will enable to carry out scientific research by taking responsibility of each student, is carried out in our faculty with an internship called "Scholarly Concentrations Program" in clinical period. The aim of this study is to explain how the practice is done and to evaluate and to share the experiences gained.

Material and Methods: In this internship, there are six modules whose purpose and content are determined. In these modules, there are conferences for research education and stages of research that students have prepared together with their advisors. Students choose a adviser among faculty member and sign a standard contract with them. A commission called the Scientific Internship Commission has been established to plan, conduct and control this program. From the first module, students should create a research question with their advisors, make scientific literature reviews, get approval from the ethics committee, and prepare a project if necessary and apply to Scientific Research Projects Unit (BAP). They also have the responsibility to receive statistical support and to continue and complete the research. In the modules, lectures are given by faculty members on research principles. Students are divided into small groups and present the stages of their projects to members of the Scientific Internship Commission and their group friends. Stages of each module have been created and published in a manual. At the end of three semesters of internship, students present their research in the form of oral or poster presentations in the "Research Day" activities organized at Medical Day. The Scientific Internship Commission organizes the program, takes part in the modules and evaluates the feedback received from all parties and reports to the 
upper units. The members of the Johns Hopkins University, which with whom we coordinate with the program, also contribute to each module. Measurement and evaluation is carried out with a structured scoring system for each module.

Results: Scholarly Concentration in 2015-2016 academic year has begun with Term IV and on 14 March 2017 a total of 93 research has been completed and presented as an oral or poster presentation. On the 14th of March 2018, 100 students, who completed the next semester successfully, completed their studies. At present, 130 students in Term IV and 126 students in Term $V$ are continuing their studies to carry out research projects. The research abstracts of 193 students have been published in the supplementary edition of Bezmialem Science, and it is planned to publish the completed projects each year.

\section{Conclusion: Scholarly Concentration is} designed to teach students scientific literacy. We think that the learning of BVU students by making and living these stages will have a significant contribution to their education. We believe that the spread of similar practices will increase the number of researcher physician in our country.

\section{GíRIŞ}

Tıp fakültesi araştırma eğitimi programlarının amacı, hekim adaylarında bilimsel araştırmalarla ilgili yetkinlikleri ve yeterlilikleri kazandırmaktır. Araştırma eğitimleri; geleneksel tıp eğitimi programlarının yanında bağımsız bir bilimsel projenin tamamlanabilmesi için öğrencilere firsat veren seçmeli veya zorunlu deneyimleridir. Ancak araştırma eğitimi özellikle ABD ve Avrupa'daki tıp fakültelerinde çok daha önceleri başlamış ve sürdürülmektedir $(1,2)$.
Mezuniyet öncesi tıp eğitiminde, ulusal yeterlilikler çerçevesinde üç temel başlık bulunmaktadır. Bunlar; 1. Hekimlik uygulamalarıyla ilgili yeterlilikler, 2. Bilimsel yaklaşım ve araştırmaya yönelik yeterlilikler ve, 3. İnsani ve mesleki değer ve davranışlara yönelik yeterliliklerdir.

Bezmialem Vakıf Üniversitesi tıp fakültesi "Mezun Yeterlilikleri" nin altınc1 maddesinde bilimsel araştırma tasarlama sorumluluğu üstlenebilen, bilimsel araştırmaya dönüşebilen klinik sorular oluşturabilen, bilimsel araştırmalar içinde yer alabilen mezunlar yetiştirmek de belirtilmiştir.

$\mathrm{Bu}$ nedenlerle ve eğitim yöneticilerinin çaba ve planlarıyla, mezuniyet öncesi tıp eğitimimizde planlı ve düzenli araştırma eğitimi verilmek üzere hem temel bilimler müfredatında bilimsel okuryazarlığa yönelik dersler, küçük grup çalışmaları ve kanıta dayalı tıp haftası gibi programlar, hem de klinik bilimlerde "bilimsellik" başlığı ile yatay bir staj oluşturulmuştur. $\mathrm{Bu}$ program kapsamında fakültemizden mezun olan öğrencilerin hepsinin, kendi oluşturduğu bir araştırma sorusu ile araştırma yaparak mezun olması sağlanmaktadır.

Bu çalışmada, BVÜ tıp fakültesi müfredatında yer alan bilimsellik stajının; planlanma ve uygulanma aşamaları, değerlendirme yöntemi ve yaklaşık dört yıllık deneyimlerimizin paylaşılması ve tıp fakültelerinde verilen araştırma eğitimlerinin örnekleri ile tartışılması amaçlanmıştır.

\section{GEREÇ ve YÖNTEM}

\section{Uygulama aşamaları}

Mezuniyet öncesi Eğitim Koordinasyon Kurulu'nda alınan kararlarla, araştırma eğitimi kapsamında hazırlanan bu staj, yurt dışı örnekleri de göz önüne alınarak değerlendirilmiş ve 
Johns Hopkins (JH) Üniversitesinde yürütülen araştırma eğitimi programı ile eşgüdümlü olarak yapılması planlanmıştır. Bilimsellik komitesinin düzenli bir şekilde yürütülmesi ve program hazırlıkları için 12 öğretim üyesinden oluşan bir Bilimsellik Stajı Komisyonu (BSK) görevlendirilmiş olup, uygulamayla ilgili tüm ilerlemeler ilgili yönerge gereği aşamalı olarak BSK başkanı tarafından dekanlık ve rektörlüğe rapor edilmektedir.

Staj programı altı modülden oluşmaktadır. Her bir modülde araştırma eğitimine yönelik konferanslar ve her bir öğrencinin danışmanları ile hazırlamış oldukları araştırmaların aşamaları yer almaktadır. Dönem IV ve V de yürütülen ve 1.5 yı1 süren bu yatay stajın sonunda öğrenciler tamamladıkları araştırmaları 14 Mart’ta düzenlenen “Araştırma Günü” etkinliğinde sözlü veya poster bildirileri şeklinde hazırlayıp sunmaktadırlar. Her öğrencinin araştırma projesini Dönem V de tamamlayıp sunması ve bir makale ya da bildiri haline getirerek kurumsal eğitim bilgi sistemine girmesi gerekmektedir. BVÜ Tıp Fakültesi Eğitim-Öğretim ve Sınav yönergesinde de belirtildiği üzere bu durum intörnlüğe başlamanın da bir ön şartıdır.

Öğrencilerin danışmanlarılya görüşmelerinin sağlanması, araştırmalarının gerçekleşmesi için devam eden diğer stajlarının içinde (Perşembe günleri öğleden sonra) bir zaman ayrılmıştır. Öğrenciler ayrıca serbest çalışma saatlerinde danışmanlarıyla görüşebilmekte ve araştırmalarını yürütmektedirler.

Öğrencilerin ilk modülden itibaren bir araştırma sorusu oluşturabilmek için bilimsel literatür taraması yapması ve ilgi duyduğu branştan seçeceği bir öğretim üyesiyle sözleşme imzalaması gereklidir. Öğrenciler kendilerine verilen gönüllü danışman listesinden veya doğrudan kendi isteklerine göre seçerek gerekli görüşmeleri yaparlar. Öğrencilerin, araştırmalarını gruplar halinde değil, tek başlarına danışmanının desteği ile, başından sonuna kadar yürütmeleri gerekmektedir. Öğrencilerin her modülün konferans bölümlerine katılması da gerekmektedir. $\mathrm{Bu}$ konferanslar hem BVÜ, hem de JHÜ öğretim üyeleri tarafindan verilmekte olup her modülde gerçekleştirilmesi gereken aşamalarla uyumlu sunumlardan oluşmaktadır.

Öğrencilerin mentörlerinin yönlendirmesiyle yapacakları araştırmalar için gerekli hallerde etik kurul onayı almaları, Bilimsel Araştırma Projeleri (BAP) Başkanlığı'ndan proje hazırlayarak parasal destek istemeleri gerekebilir. Öğrenci araştırmaları BAP tarafından öncelikli olarak, BAP komisyonunca belirlenen bir tutarda desteklenmektedir. Hayvan deneyleri yapılması planlanıyorsa deney hayvanı kullanımına yönelik sertifikanın alınması düzenli verilen kurslarla sağlanmaktadır.

\section{Modüller}

Belirlenen her modülün gerektirdiği bir aşama bulunmaktadır. Öğrencilerin her modülün gerekli işlemlerini yerine getirmeleri tam puan alabilmeleri için gereklidir.

Eğitim-Öğretim Rehberi'nde de belirtilmiş olan bu modüller iki tam gün olarak planlanmaktadır. Modüllerin ilk gününde, BSK'y1 oluşturan öğretim üyeleri, konuyla ilgili olarak $\mathrm{o}$ dönemdeki öğrencilerin tümüne konferanslar vermekte, öğrencilerin bilimsel araştırmalarda kullanabilecekleri temel bilgilere ulaşmaları için yol göstermektedirler. İkinci günde ise öğrenciler, ikinci modülden itibaren senkronize küçük gruplar halinde (ortalama 10 kişilik) hangi aşamada olduklarını, kendilerine ayrılan 10 dakikalık sürede sözlü sunumlar şeklinde küçük gruba ve BSK üyesine sunmaktadırlar.

2015 yılında başlatılan ve dört yıldır düzenli olarak sürdürülen, 1.5 yıl boyunca yatay bir 
staj olarak devam eden bu eğitim programında; temel bilimlerden araştırma eğitimi modelimizle ilgili bilgilendirmelerle Dönem IV'e başlayan öğrencilere eğitimin başladığı ilk hafta 1 . Modül uygulanmaktadır. $\mathrm{Bu}$ modülde yöntem tanıtılmakta, amaç ve hedefler paylaşılmaktadır. Tüm modüllerin içerikleri Tablo 1 de sunulmuştur

Her modül arasında en az iki aylık bir süre vardır. Modüller klinik stajlar içine entegre edilmiş bir staj olarak uygulanmaktadır.

Tüm modüller JH üniversitesi tıp eğitimi öğretim üyeleri tarafından izlenmekte ve her modül sonrası BSK ile yapılan geri bildirim toplantılarında gelişmeler tartışılmaktadır. Böylece eğitimimizin bu bölümünde aynı zamanda bir dış değerlendirme süreci de uygulanmaktadir.

Ayrica her modül sırasında öğrencilerden, verilen konferanslarla ve bilimsellik stajiyla ilgili geri bildirimler, hem yapılandırılmış anketlerle hem de açık uçlu sorularla alınmakta, değerlendirilmekte ve paylaşılmaktadır.

\section{Sonuçlanan araştırmaların sunumu}

Araştırma gününden bir ay öncesine kadar öğrencilerin, bitmiş araştırmalarının özetlerini eğitim bilgi sistemine yüklemeleri beklenir. Özetlerin hangi formatta yazılacağı belirlenmiş ve bir örneği önceden duyurulmuştur. Sisteme yüklenen özetler incelenerek hangi araştırmanın hangi formatta sunulacağına BSK tarafından karar verilir ve öğrencilere duyurularak hazırlanmaları için zaman verilir. Büyük gruba sözlü sunum, küçük gruplara sözlü sunum ve poster sunumları olarak ayrılan araştırma sunumlar1, bir bilimsel kongre atmosferinde gerçekleştirilir. Fakülte içi ve dışından oluşturulan bağımsız bir jüri bu çalışmaları izler, değerlendirir ve puanlama yapar. Her sunum grubu için farklı bağımsız jüriler oluşturulmaktadır. Jürilerin puanlamaları BSK tarafindan değerlendirilerek ilk 8-10 öğrenci ve projesi seçilir. $\mathrm{Bu}$ öğrenciler ve danışmanları ödüllendirilir.

BSK tarafından tüm aşamalar ve süreçler ile ilgili olarak bir uygulama kılavuzu oluşturulmuştur. $\mathrm{Bu}$ kılavuz ve programlar öğrencilerin hepsine uygulamalar öncesinde dağıtılmakta ve bilgilendirilmeleri sağlanmaktadır. Araştırma günü için de ayrıca sunumların yeri ve içerikle ilgili ayrıntılı bir program oluşturularak gerekli duyurular yapılır.

\section{Ölçme ve değerlendirme aşamaları}

Araştırma projesini tamamlamayan, sunum ya da makale haline getirerek Kurumsal Eğitim Bilgi sistemine yüklemeyen öğrenci başarısız sayılır. Danışman değişmesi ve benzeri nedenlerle araştırmasını tamamlayamayan öğrenciler bu işlemleri intörnlük aşamasına kadar tamamlamak zorundadır. Öğrencilerin bu stajdan geçebilmesi için en az 60 puan almış olması gerekmektedir.

Öğrenciler her modüldeki konferanslara katılımları, sunumlarının niteliği ve modülün gerektirdiği aşamalar yönünden değerlendirilirler. İlk uygulamalarımızda öğrencilerin her modülden aldıkları puanlar, öğrencinin bulunduğu staja eklenmekteyken, BSK tarafindan daha sonra tamamen ayrı bir staj olarak değerlendirilmesi kararı alınmıştır. Bu şekliyle doğrudan transkriptlerine de yansıyan bir staj haline dönüştürülmüştür.

Tüm modüllerin puanlamaları Tablo 2. de sunulmuştur. 
Özetleri yayınlanan bu çalışmalar çok farklı konuları içermektedir. Tek bir konuda yoğunluk bulunmamakta olup, dahili, cerrahi ve temel tip bilimlerinden seçimler yapıldığı görülmektedir (Tablo 4). Her dönem öğrencinin seçmiş olduğu konulara göre dağıllım değişiklik gösterebilmektedir. Bazı çalı̧̧malarda ise birkaç disiplinden daha destek alınması gerekmektedir.

Öğrenciler her aşamada kendisine verilen notları, eğitim bilgi sisteminden görebilir. Araştırmasını tamamlamasına karşın modüllerden yeterli bir puan alamayan öğrenci bütünlemeye kalır. 1.5 yıllık modüllerden aldığ 1 puanların $\% 30$ 'u, araştırmayla ilgili yapılan sözlü sınavdan alınan puanın \%70'i alınarak bütünleme notu hesaplanmaktadır.

\section{Uygulama sonuçları}

2015-2016 Eğitim - Öğretim y1lında Dönem IV de başlanan bu yöntemle; 14 Mart 2017 tarihinde toplam 93 araştırma tamamlanarak sunulmuştur. Bir sonraki dönem devam eden 100 öğrenci de 14 Mart 2018 tarihinde araştırma gününde aynı şekilde 100 farklı araştırma projesini başarıyla tamamlamış ve sunmuştur (Tablo 3). Halen Dönem IV de 130, Dönem V'de 126 öğrenci araştırma projelerini gerçekleştirmek üzere çalışmalarına devam etmektedir. 193 öğrencinin araştırma özetleri Üniversitemizin dergisi Bezmialem Science'ın ek sayısı olarak yayınlanmış olup, bu yıl sunulacakların özetlerinin de yayınlanması için hazırlıklar devam etmektedir.

Modüller sırasında öğrencilerden düzenli olarak alınan geribildirimler değerlendirilmekte ve JHÜ ile paylaşılmakta ve bir diş değerlendirme sürecine tabi tutularak değerlendirilmekte ve raporlanmaktadır. 2018-2019 eğitim-öğretim yılında uygulanan Modül 1 den alınan geri bildirimler değerlendirildiğinde; sekiz farklı bilgilendirme ve konferans yer almış olup öğrencilerin sunumlara verdiği puanlamalar; \%36-63 oranında Mükemmel, \%28-48 oranında Çok iyi, \%3-17 oranında Yeterli, \%1-4 arası Kısmen yeterli, \%0-1 Kötü olarak saptanmıștır. Öğrenciler, açık uçlu sorulara verdikleri yanitlarda, genellikle uygulamadan memnun olduklarını ancak seçmek istedikleri konularda bazen danışman bulmakta zorlandıklarını ifade etmişlerdir.

BSK üyelerinin kendi içinde yaptığ 1 geribildirimler ve aldığ toplantı kararları ise kayda alınarak ilgili kurul ve komisyonlara aktarılmaktadır. Her yıl danışmanlarla de en az bir toplantı düzenlenmekte ve onlardan da işleyiş ve süreç hakkında geribildirimler alınmaktadır. 
Günümüze kadar tamamlanan araştırmalardan birçoğu konu ile ilgili kongrelerde, bildiri olarak sunulmuştur. Bunların bazıları ödül almıştır. Birçok araştırma da öğrenci ve danışmanı ile birlikte araştırma makalesi haline çevrilerek yurtiçi ve yurt dışı dergilerde yayınlanmaya başlamıştır.

\section{Tartışma}

Tıp fakültelerinde planlanan araştırma eğitimi programlarının amacı, hekim adaylarının bilimsel araştırmalara ilgi ve yetkinliklerini arttırmaktır. Ülkemiz dışında verilen tıp eğitimlerinde bunların örnekleri ve uygulamalar hakkında çok sayıda veri bulunurken yurt içindeki uygulama modelleri ile ilgili bu konuda yayınlanmış veriler oldukça kısıtlıdır (1).

Son yıllarda ABD'de hekim-araştırmacı sayısında düşüş olduğu tespit edilmiş ve bu eğilimi tersine çevirmek için $\mathrm{MD} / \mathrm{PhD}$ (Doktora) programlarına, alt uzmanlık gruplarında araştırmalara yönelme gibi birçok mekanizma önerilmiştir. Bunların yeterli olmadığı henüz tıp öğrencisiyken araştırma deneyimlerinin edinilmesinin daha etkili bir çözüm olacağ1 düşünülmüştür (2). Aslında birçok tıp fakültesinde araştırma eğitimi ya da bitirme tezi olarak araştırma, normal müfredatlarında yer almaktadır. JHÜ de uygulanan ve 18 ay süren araştırma eğitimi, öğrencilerine temel veya klinik araştırmalar, tıp tarihi, halk sağlığ1 veya biyoetik gibi konuları içeren araştırmalar yapmak için olanak sağlamaktadır. Öğrencilerin ilgi alanlarına bağlı olarak araştırma yapmalarına firsat verilmektedir. Her yaz, yaklaşık 100 öğrenci JH destekli araştırma bursları ile her türden araştırmayı yürütmektedir (3). JHÜ uygulamasina benzer olan BVÜ uygulaması da başarıyla sürdürülmektedir.

Yale Üniversitesi Tıp Fakültesi, mezuniyet için orijinal araştırmaya dayalı bir tez gerektiren tıp fakültesidir. Müfredatın önemli bir parçası olan tezin, eleştirel düşünme, kendi kendine öğrenme alışkanlıkları ve bilimsel yöntemin tıbba uygulanması için tasarlandığı belirtilmiştir. 1839'dan beri gerekli olan bu tez, öğrencilere akademisyenlerle yakından çalışma firsatı vermektedir. Yale tıp öğrencilerine, araştırmanın planlanması, uygulanması ve tamamlanması konusunda yardımc1 olunmaktadır. Tez konusundaki araştırmaları kolaylaştırmak için, öğrencilere yaz araştırması ödülleri, kısa süreli öğrenci araştırmaları, bir yıllık öğrenci araştırma bursları olarak üç tip destek verilmektedir. Öğrencilerin laboratuvar araştırması, klinik araştırma, çeviri araştırması, epidemiyoloji ve halk sağlığı araştırması, uluslararası araştırma, eğitim araştırması, nitel araştırma, tıp tarihi ve biyoetik dahil olmak üzere tıpta beşeri bilimlerde araştırmalar yapılmaları sağlanmaktadır. Finansman için tüm başvurularda öncelikle hipotez oluşturulmalıdır. V. Sınıf öğrencileri Mayıs ayında yapılan yıllık Öğrenci Araştırma Günü'nde poster oturumları ve sözlü sunumlarda araştırmalarını sunmaktadirlar(4). Benzer uygulamalara yurt içinde bazı fakültelerimizde rastlanmış olmakla beraber modelle yayınlanmış bir veri henüz bulunmamaktadır.

Vanderbilt Üniversitesi, 25 yıldır devam eden Ulusal Sağlik Enstitüleri (NIH) -Sponsorlu Tıp Öğrenci Araştırma Bursu programlarıyla (MSRFs) yürüttükleri araştırma eğitimlerini değerlendirerek yayınlamışlardır. Üniversiteye ait programda, ögrenciler, birinci ve ikinci sınıf yaz aylarında, bir öğretim üyesi tarafından yönlendirilerek yapılandırılmış bir programda çalışmaktadırlar (2). $\mathrm{Bu}$ deneyimi halen yaşayan, daha önce almış, yıllar önce almış 1000 kişiden geribildirim alınmıştır. Eski öğrencilerin büyük çoğunluğu tıp öğrencisi araştırma deneyiminden sonra ek araştırmalar 
yapmış, halen araştırmalar yapmakta ve çalışmalarını bilimsel toplantılarda sunmakta olduklarını belirtmişlerdir. $\mathrm{Bu}$ çalışmada; $\mathrm{NIH}$ destekli tıp öğrenci araştırma programlarıyla yirmi yıllık deneyim, bu programların araştırma ve akademik kariyerlerinde tıp öğrencilerine yararlı olduğu, verilen bu bursların hekim-bilim insanı sayısındaki düşüşü tersine çevirebileceği bildirilmiştir (2). Aynı üniversitede 2018 de yayınlanan bir başka çalışmada programın çıktıları yeniden değerlendirilmiş ve uygulanan araştırma eğitimi programının mezunlarına kattığ 1 olumlu etkiler tartışılmıştır (5).

Öğrenci araştırmalarını inceleyen bir metaanalizde tıp öğrencilerinin araştırmaya katılımının etkisini değerlendiren tüm ilgili nicel ve nitel çalışmalar belirlenmiş ve 256 makaleden 79'u çalışmaya alınmıştır. Yapılan analizlerde, araştırmaya katılan tıp öğrencilerinde, kısa ve uzun dönemli bilimsel üretkenlikte artış olduğu, daha bilinçli kariyer seçimi yapabildikleri ve araştırma yapmaya daha fazla ilgi duydukları belirlenmiştir (6).

Bir diğer meta-analiz çalışmasında öğrenciler; genellikle tıp fakültesi araştırma deneyimlerinin, araştırma ilgisini uyandırmak ve bilimsel araştırma yeteneklerini geliştirmek açısından olumlu olduğunu bildirmişlerdir. Öğrencilerin çoğunluğu en az bir makale yazmış ve araştırma deneyimleri uzadıkça daha çok ilk yazar olarak makale yayınladıkları belirlenmiştir. Seçmeli deneyimlerin, öğrenci memnuniyeti veya üretkenlik açısından zorunlu deneyimlerden farklı olmadığı da bu çalışmada bildirilmiştir. $\mathrm{Bu}$ bulgular, tıp öğrencisi araştırma programlarının, öğrenci çabalarını ödüllendirerek, öğrenci-danışman etkileşimini teşvik ederek ve öğrencilere araştırma deneyiminin süresini artırma seçeneği sunarak optimize edilebileceğini göstermektedir (7). Biz de fakültemizdeki uygulamanın etkilerini, mezunlarımızın yapmış olduğu yayınlardan ve akademik çalışmalarından izlemeyi planlamaktayı.

"Scholarly Concentration (SC) programlarının tıp öğrencilerine ne gibi bir etkisi var?" sorusunu araştıran bir başka çalışmada; 2008 yılında yazarlar elektronik veri tabanlarını ve atıfları tarayarak elde ettikleri makaleleri değerlendirmişlerdir. Yapılandırılmış bir form kullanarak seçilmiş makalelerin verilerini çıkarmışlar ve 39 makale çalışmaya dahil edilmiştir. $\mathrm{Bu}$ makalelerde, öğrencilerin SC deneyimlerinin klinik uzmanlık seçimlerini etkilediğine ya da araştırmaya olan ilgilerini artırdığına dair kanıt sağlamıştır. Ayrıca, bu programların öğrencilerin araştırma ilke ve yöntemlerini anlamalarını, edinilen bilgi ve becerileri uygulamak için yayınlar ve sunumlar yaptıklarını, SC programını alan mezunların akademik çalışmalara devam isteklerinin almayanlara göre fazla olduğu gösterilmiştir. Ancak klinik dönemde yaptıkları bu araştırmalara yeterince zaman ayırmakta zorlandıklarını da belirtmişlerdir (8).

Duke Üniversitesi tıp fakültesi, öğrencilerinin bilimsel deneyim kazanmalarını sağlamak için 1959 yılında araştırma eğitimi programını oluşturmuştur. Başlangıçta laboratuvar temelli temel araştırma deneyimini desteklemek için tasarlanan program, tıptaki gelişmeler nedeniyle bazı değişimlerle uygulanmaya devam etmektedir. Stanford Üniversitesi de biyomedikal araştırmalara uzun süredir devam eden bir yapıya sahiptir ve mevcut programlarında her öğrencinin bir danışman yönlendirmesiyle mezun olana kadar, bilimsel bir araştırma yapma zorunluluğu bulunmaktadır. Bilimsel araştırma deneyimlerinin çoğunun üçüncü yılda gerçekleştiği Duke' un aksine, Stanford programında dört yıllık tıp fakültesi eğitimi boyunca süren, bir program bulunmaktadır. 
$\mathrm{Bu}$ deneyimlerin öğrencileri akademik tıp alanında kariyer yapmaya motive edebileceği belirtilmektedir(9). $\quad \mathrm{Bu}$ üniversitelerin uygulamaları da BVÜ uygulamamıza benzerlik göstermektedir.

Norveç’te tıp fakültesi öğrencileri için, Öğrenci Araştırma Programı başlı̆̆ı altında ulusal bir eğitim ve burs programı oluşturulmuştur. Araştırma Programı 2002 yılında kurulmuş ve 2007 baharında kapsamlı bir değerlendirmeye alınmıştır. Veriler, web tabanlı anketler aracılığıyla öğrencilerden, yöneticilerden ve idari personelden toplanmıştır. Kabul, uygulama, elde edilen sonuçlar ve memnuniyet ile ilgili bilgiler analiz edilerek dört Norveç tıp fakültesi arasında karşılaştırma yapılmıştır. Bu programı tamamlamış olan öğrencilerin hepsi bir ya da birkaç bilimsel makale yayınlamıştır. Dört tıp fakültesi arasında yukarıda belirtilen başlıklarla ilgili önemli farklar gözlenmemiştir. Öğrenci Araştırma Programının, mezun hekimlerin Norveç'te tıbbi araştırmalara alınmasında artışa yol açtı̆̆

Diğer taraftan, bilimsel eğitim ve araştırma eğitimine büyük çaba sarf edildiği, ancak bu çabaların çıktısının net olarak bilinmediğini belirten bir diğer çalışmada; Hollanda'da Web of Science veri tabanında yapılan taramalarda öğrencilerinin \% 14.5' inin tıp eğitimlerinin son 3 yılında en az bir bilimsel makale yayınladığını saptamışlardır. $\mathrm{Bu}$ incelemede makale başına ortalama atıf sayısının yüksek olduğu belirtilmiştir. Araştırma sonuçlarına dayanarak, Hollanda'daki tıp fakültesi öğrencilerinin araştırmalara verimli bir şekilde katıldıkları, daha büyük ölçekte taramalarla, araştırma eğitiminin, tıp fakültesi öğrencileri arasında akademik yeteneklerin ortaya çıkarılması ve geliştirmesi için teşvik edici olduğu kanısına varılmıştır (11).
Sonuç olarak;

1. BVÜ tıp fakültesi araştırma eğitim programı dört yıldır başarıyla sürdürülmektedir.

2. $\mathrm{Bu}$ süreçte başarıyla sonlandırılan 193 araştırma özeti yayınlanmış olup bazıları makale halinde de hakemli dergilerde yayınlanmıştır.

3. Halen Dönem IV ve V öğrencileri 156 araştırmayı sürdürmektedir.

4. Tıp fakültelerinin tıp eğitiminde uygulanan araştırma eğitimlerinde yurtiçi ve yurt diş1 örnekleri ele alındığında bir standart uygulama olmadığ1 görülmekte olup fakültemizde uygulanan model yurtiçi için bir örnek oluşturmaktadır.

5. Fakültemizde uygulanan sistemin daha fazla hekim-araştırmacı yetişmesinde etkin bir yöntem olup olmadığını ancak mezun izlemleriyle saptamamız mümkün olabilecektir. 6. Öğrenci araştırmalarından oluşturulan makalelerin aldığı atıfların saptanması, mezunlarımızın daha sonra ürettiği yayınların sayısı, akademisyenliği tercih edenlerin oranı gibi veriler biriktiğinde bu eğitimin ne kadar yararlı olduğu daha net anlaşılabilecektir.

\section{Teşekkür}

$\mathrm{Bu}$ eğitim programının gerçekleşmesinde öncü rol oynayan JHÜ Bilimsellik komitesi (Scholarly Concentration Module) akademisyenleri Mary Catherine Beach ve Stephen Sozio başta olmak üzere programımıza aktif katılımda bulunan tüm öğretim üyelerine, Programın geliştirilmesi ve yürütülmesinde katkısı bulunan BVÜ Bilimsellik komitesinde görev alan öğretim üyelerine ve danışmanlık görevini yürüten tüm öğretim üyelerine çok teşekkür ederiz. 


\section{KAYNAKLAR}

1.Akman M, Unalan PC, Kalaca S, Apaydin KÇ, Cifcili S, Uzuner A. A Three-Year Mandatory Student Research Program in an Undergradute Medical Curriculum in Turkey Kuwait Medical Journal 2010; 42 (2): 106-111

2. Solomon SS, Tom SC, Pichert J, Wasserman D, Powers AC. Impact of medical student research in the development of physicianscientists.J Investig Med. 2003; 51:149-156.

\section{Research Opportunities .Johns Hopkins School} of Medicine https://www.hopkinsmedicine. $\mathrm{org} / \mathrm{som} / \mathrm{admissions} / \mathrm{md} / \mathrm{research} / \mathrm{index} . \mathrm{html}$ Accessed January 2019

4. Office of Student Research. Yale School of Medicine. http://medicine.yale.edu/education/ osr/index.aspx. Accessed January 2019

5. Brown MA, Chipps TM, Gebretsadik T, Ware LB, Islam JY, Finck LR, Barnett J, Hartert TV. Training the next generation of physician researchers - Vanderbilt Medical Scholars Program. BMC Medical Education 2018; 18:5 DOI 10.1186/s12909-017-1103-0

6. Amgad M, Man Kin Tsui M, Liptrott SJ, Shash E. Medical student research: an integrated mixed-methods systematic review and meta-analysis. PLoS One 2015; Jun 18;10(6):e0127470. doi: 10.1371/journal. pone. 0127470 . eCollection 2015

7.Chang Y, Ramnanan CJ. A review of literature on medical students and scholarly research: experiences, attitudes, and outcomes. Acad Med. 2015;90:1162-1173
8. Bierer SB, Chen HC. How to measure success: the impact of scholarly concentrations on students - a literature review. Acad Med. 2010;85:438-452.

9. Laskowitz DT, Drucker RP, Parsonnet J, Cross PC, Gesundheit N. Engaging students in dedicated research and scholarship during medical school: the long-term experiences at Duke and Stanford. Acad Med. 2010;85:419428.

10. Hunskaar S, Breivik J, Siebke M, Tommeras K, Figenschau K, Hansen JB.

Evaluation of the medical student research programme in Norwegian medical schools. A survey of students and supervisors. BMC Medical Education 2009; 9:43 doi:10.1186/1472-69209-43

11. van Eyk HJ, Hooiveld MH, Van Leeuwen TN, Van der Wurff BL, De Craen AJ, Dekker FW; NVMO-Special Interest Group on Scientific Education. Scientific output of Dutch medical students. Med Teach. 2010;32(3):2315. doi: $10.3109 / 01421591003596592$ 